\title{
Sexually Transmitted Infections in Soldiers - A Cross-Sectional Assessment in German Paratroopers and Navy Soldiers and a Literature Review
}

\author{
Carina Gottwald ${ }^{1}$, Norbert Georg Schwarz ${ }^{2}$ and Hagen Frickmann ${ }^{3,4 *}$ \\ ${ }^{1}$ Bundeswehr Military Medical Department Wilhelmshaven, Wilhelmshaven, Germany \\ ${ }^{2}$ Infectious Disease Epidemiology, Bernhard Nocht Institute for Tropical Medicine Hamburg, Hamburg, Germany \\ ${ }^{3}$ Department of Microbiology and Hospital Hygiene, Bundeswehr Hospital Hamburg, Hamburg, Germany \\ ${ }^{4}$ Institute for Medical Microbiology, Virology and Hygiene, University Medicine Rostock, Rostock, Germany
}

Received: 07 Oct 2019; accepted: 14 Oct 2019

\begin{abstract}
Introduction: The study was performed to estimate the prevalence and determinants of occurrence of sexually transmitted infections (STIs) in paratroopers and navy soldiers by anonymously analyzing medical records from the medical departments of two large German barracks in order to assess the need for medical STI prevention.

Methods: Medical records from 80 paratroopers and 80 navy soldiers were screened for records of STI. Results were anonymously collected next to information on risk factors, as well as diagnostic and therapeutic management, and comparatively assessed.

Results: Proportions of suspected STIs were $17.5 \%$ and $20 \%$, and proportions of diagnosed STIs were $13.9 \%$ and $11.3 \%$ for paratroopers and navy soldiers, respectively. Chlamydia trachomatis, human papillomavirus, and genital scabies were observed in paratroopers and navy soldiers, while Gardnerella vaginalis, herpes simplex virus, Molluscum contagiosum virus, Neisseria gonorrhoeae, and Trichomonas vaginalis were additionally identified in navy soldiers.

Conclusions: Although clinical hints for STIs were frequently observed, clinical management was usually restricted to syndrome-based antibiotic treatment without detailed diagnostic workup, leaving room for procedural improvement. Ongoing need for medical STI prevention in the military could be confirmed.
\end{abstract}

Keywords: STI, sexually transmitted infection, soldier, navy soldier, paratrooper, risk assessment, management

\section{Introduction}

Prevalence data on sexually transmitted infections (STIs) in soldiers are scarce and frequently based on retrospective, cross-sectional assessments focusing on selected pathogens or syndromes. In comparison to other armed forces, most reliable data are available for the US military. Between 2006 and 2015 , e.g., average prevalence was $1.3 \%$ for chlamydiae and $0.2 \%$ for gonococci in US active duty personnel [1]. Between 2000 and 2012, the 5 most frequent STIs in active US service members were caused by human papillomavirus (HPV), chlamydiae, herpes simplex virus, gonococci, and Treponema pallidum in a declining order [2]. When focusing on female US Air Force recruits; prevalence values for chlamydiae and genital herpes simplex virus (HSV) were $4.8 \%$ and $4.3 \%$, respectively, between 2012 and 2014 [3].

Human immunodeficiency virus (HIV) infections were shown to be associated with high incidence rates of other STIs like HSV infections in US Army and Air Force soldiers [4, 5]. Of note, HSV is transmitted via smear infection, so condombased protection is considerably less effective than for spermor lubrication-fluid-transmitted STIs [6]. US Navy and Marine Corps men infected with HIV showed an infection rate of $24 \%$ for either Neisseria gonorrhoeae or Chlamydia trachomatis with high rates of asymptomatic carriage in the rectum

\footnotetext{
*Author for correspondence: Department of Tropical Medicine at the Bernhard Nocht Institute, Bundeswehr Hospital Hamburg, Bernhard Nocht street 74, D-20359 Hamburg, Germany; E-mail: Frickmann@bni-hamburg.de.
}

or pharynx, stressing the need for three-site-screenings [7]. Altogether, $45 \%$ to $69 \%$ of diagnosed STIs in HIV-positive US active duty military personnel were detected more than 1 year after the diagnosis of HIV infection, indicating ongoing highrisk sexual contacts [8].

About $2 \%$ of STIs in US active duty personnel between 2005 and 2016 had been acquired on deployment; however, the authors argued that this proportion might be underestimated due to a reporting bias [1]. In line with such findings, a recent review indicated an increased association of STI transmission within the military community rather than due to sexual encounters with foreigners on deployment for the French and US military. Risky sexual practices and an increased proportion of deployed female soldiers were discussed as potential reasons for high rates of STIs in soldiers on deployment [9].

In point-prevalence assessments, observed proportions of STI-infected soldiers were sometimes considerably higher than in population-based surveillance. In a point-prevalence assessment with randomly chosen US Navy service women between 18 and 25 years of age in San Diego, California, genital infections with chlamydiae were observed in $10 \%$ with 5 out of 6 patients being anorectally infected as well. More than $20 \%$ of the assessed female soldiers reported condomless anal intercourse during their last sexual encounter as a risk factor for STI transmission. About $75 \%$ of the assessed 60 young women reported sex with casual partners; among this proportion, more than $40 \%$ reported never or rarely using condoms. Consumption of alcohol was frequent in the cohort [10]. In

This is an open-access article distributed under the terms of the Creative Commons Attribution-NonCommercial 4.0 International License (https://creativecommons.org/licenses/by-nc/4.0/), which permits unrestricted use, distribution, and reproduction in any medium for non-commercial purposes, provided the original author and source are credited, a link to the CC License is provided, and changes - if any - are indicated. 
another point-prevalence study with male US soldiers, $8 \%$ infections with chlamydiae were recorded; $63 \%$ of the infected soldiers had not used condoms during their most recent sexual intercourse [11].

In comparison to the US military, less data on STIs in soldiers are available from other countries in the international scientific literature. In Brazilian soldiers, a confirmed syphilis rate of $1.1 \%$ [12] and an HIV rate of $0.1 \%$ [13] have recently been published, with a 10 -fold increased HIV rate in men having sex with men (MSM) [13]. In Belize, 1.1\% HIV and 12\% STIs were reported for personnel in the Belize Defense Force [14]. In sexual active recruits of the Afghan National Army (ANA), low STI prevalence for HIV $(0.06 \%)$, syphilis $(0.65 \%)$, HCV $(0.82 \%)$, and HSV-2 $(3.03 \%)$ was documented in spite of a quantitatively relevant minority reporting sexual risk practices like paying women for sex $(21.3 \%)$ and sex between males (also 21.3\%) [15]. In a Korean study assessing soldiers with urethritis, the most frequently identified suspected causative agents were $N$. gonorrhoeae $(19.0 \%)$, C. trachomatis (36.6\%), Ureaplasma urealyticum (24.0\%), Mycoplasma genitalium (21.5\%), Mycoplasma hominis (6.1\%), HSV type $2(1.6 \%)$, and Trichomonas vaginalis $(0.2 \%)$. In $9.4 \%$ of the cases, the causative agent could not be identified, and co-infections were observed in $5.7 \%$ of the study participants [16]. Of note, the relevance of $U$. urealyticum and M. hominis as STI-associated pathogens has to be considered as questionable as suggested by recent data [17].

Few data are available for European armies as well. The French military reported an STI rate of $4.7 \%$ with $C$. trachomatis being the quantitatively by far dominating infectious agent [18]. Only $0.2 \%$ STI infections were detected in the course of a voluntary screening assessment in the Estonian army [19]. Similarly, a very low proportion of only $0.8 \%$ infections with $C$. trachomatis was observed in a military cohort in Poland, although $40 \%$ of the population reported sexual contacts with 2-4 and more partners within 12 months prior to the assessment [20].

In the cross-sectional study presented here, experience with STI detections from two large barracks for paratroopers and navy soldiers in Germany is presented. The study was performed to assess the need for medical STI prevention in the German military.

\section{Methods}

Retrospectively Assessed Medical Records. A total of 80 medical records of German paratroopers from barracks with 2356 army soldiers and 80 medical records of German navy soldiers from barracks with 5129 navy soldiers were randomly selected for retrospective assessment. Patientrelated data were anonymously recorded in a Microsoft Excel version 2007 (Microsoft Corporation, Redmond, USA) spreadsheet.

Anonymously Assessed Patient Data. Anonymously assessed patient data comprised the patients ages (at the time of STI detection in the case of STI-positive patients or at the time of viewing the files in the case of patients without any STI), gender, rank group, diagnosis of sexually transmitted diseases or syndromes, localization of the infection, clinical versus laboratory confirmed diagnosis, documentation of partner therapy to avoid ping pong infections, history of risk factors, deployment area in the case of infection on deployment, marital status, and number of infection events in the case of repeated infections. The frequencies of STI detections and risk exposures were stratified according to service membership.

Statistics. Due to the low number of assessed patient files, only descriptive assessment was performed.

Ethics. The blinded retrospective assessment of medical records was allowed by the Ethics Committee of the Medical Association of Hamburg, Germany (registration number WF021/18) in line with national laws.

\section{Results}

Patient Populations. As detailed in Table 1, both the populations of paratroopers and navy soldiers were predominantly male and of comparably young age. On average, acquisition of STIs occurred in the second half of the third decade of the patients' life. The distribution of ranks was comparable for the junior and senior commissioned officers, while the proportion of officers was higher in the population of the navy soldiers, and more privates were among the paratroopers. In general, the proportion of married soldiers was low in both groups, while living as singles or unmarried

Table 1. Characterization of the assessed populations of paratroopers and navy soldiers. Not all assessed parameters were available for all patients

\begin{tabular}{|c|c|c|}
\hline & Paratroopers $(n=80)$ & Navy soldiers $(n=80)$ \\
\hline Females in $\%(n)$ & $5 \%(4 / 80)$ & $1.3 \%(1 / 80)$ \\
\hline Median age in years & 28 & 29 \\
\hline Mean age in years $( \pm$ standard deviation $S D)$ & $27.5( \pm 5.7)$ & $32.0( \pm 10.2)$ \\
\hline Median age of STI patients in years & 26.5 & 26 \\
\hline Mean age of STI patients in years ( \pm standard deviation SD) & $26( \pm 3.7)$ & $26.8( \pm 4.9)$ \\
\hline Officers in $\%(n)$ & $2.5 \%(2 / 80)$ & $17.5 \%(14 / 80)$ \\
\hline Senior non-commissioned officers in \% $(n)$ & $15 \%(12 / 80)$ & $22.5 \%(18 / 80)$ \\
\hline Junior non-commissioned officers in \% $(n)$ & $22.5 \%(18 / 80)$ & $31.3 \%(25 / 80)$ \\
\hline Privates in $\%(n)$ & $60 \%(48 / 80)$ & $28.8 \%(23 / 80)$ \\
\hline Previous deployments in \% $(n)$ & $42.5 \%(34 / 80)$ & $48.8 \%(39 / 80)$ \\
\hline Without primary partnership in \% $(n)$ & $39.1 \%(9 / 23)$ & $42.9 \%(18 / 42)$ \\
\hline With primary partnership, not married in $\%(n)$ & $47.8 \%(11 / 23)$ & $33.3 \%(14 / 42)$ \\
\hline With primary partnership, married in $\%(n)$ & $13.4 \%(3 / 23)$ & $23.8 \%(10 / 42)$ \\
\hline Documented sexual risk behaviors in \% $(n)$ & Not documented & $25 \%(1 / 4)$ \\
\hline Documented sexual contacts with multiple partners in \% $(n)$ & Not documented & $25 \%(1 / 4)$ \\
\hline Unprotected sexual intercourse in \% $(n)$ & $90.9 \%(10 / 11)$ & $100 \%(7 / 7)$ \\
\hline STI in medical history in $\%(n)$ & $100 \%(3 / 3)$ & $66.7 \%(4 / 6)$ \\
\hline Anal sexual intercourse in $\%(n)$ & Not documented & $0 \%(0 / 3)$ \\
\hline Vaginal sexual intercourse in \% $(n)$ & Not documented & $100 \%(4 / 4)$ \\
\hline Oral sexual intercourse in $\%(n)$ & Not documented & $0 \%(0 / 2)$ \\
\hline Men-having-sex-with-men (MSM) in \% (n) & Not documented & $0 \%(4 / 4)$ \\
\hline Sexual intercourse with different sex (heterosexual) in \% $(n)$ & $100 \%(1 / 1)$ & $100 \%(4 / 4)$ \\
\hline Bisexual contacts in $\%(n)$ & Not documented & $0 \%(0 / 4)$ \\
\hline Number of sexual partners within the previous 3 months (number of documentations) & Not documented & $0(4)$ \\
\hline Total number of sexual partners ( $x$ number of documentations) & Not documented & $0(1 x), 2(1 x)$ \\
\hline
\end{tabular}


but with a primary partnership was the most frequently observed lifestyle.

Due to very low proportions of respective documentation in the medical records, data on specific risk factors for STI acquisition could hardly be extracted. As far as documented, the records suggested a high affinity of both paratroopers and navy soldiers to unprotected sexual intercourse.

Distribution of STIs among Paratroopers and Navy Soldiers. STIs were clinically suspected in $17.5 \%$ of the paratroopers and $20 \%$ of the navy soldiers at least once as shown in Table 2. Diagnostic confirmation of STIs was successful in $13.9 \%$ and $11.3 \%$ of the paratroopers and navy soldiers, respectively. Medical documentation suggested only one case of STI acquisition on deployment for the navy soldiers and no respective events for the paratroopers, although nearly half of the assessed patients in both groups had deployment experience. In a relevant minority of about $20 \%$, partner therapy was neglected, and especially for the navy soldiers, considerable delay between onset of clinical symptoms and medical assessments was registered. While pharmacological therapy was always initiated, and adherence with national guidelines was acceptable with more than $80 \%$, adherence with diagnostic therapy control was poor with proportions of about $50 \%$, while clinically apparent recurrences were occasionally observed.

Focusing on diagnostically confirmed STI-related pathogens, $C$. trachomatis $(n=3)$, human papillomavirus $(n=4)$,

Table 2. Suspected and confirmed STI in the assessed paratroopers and navy soldiers

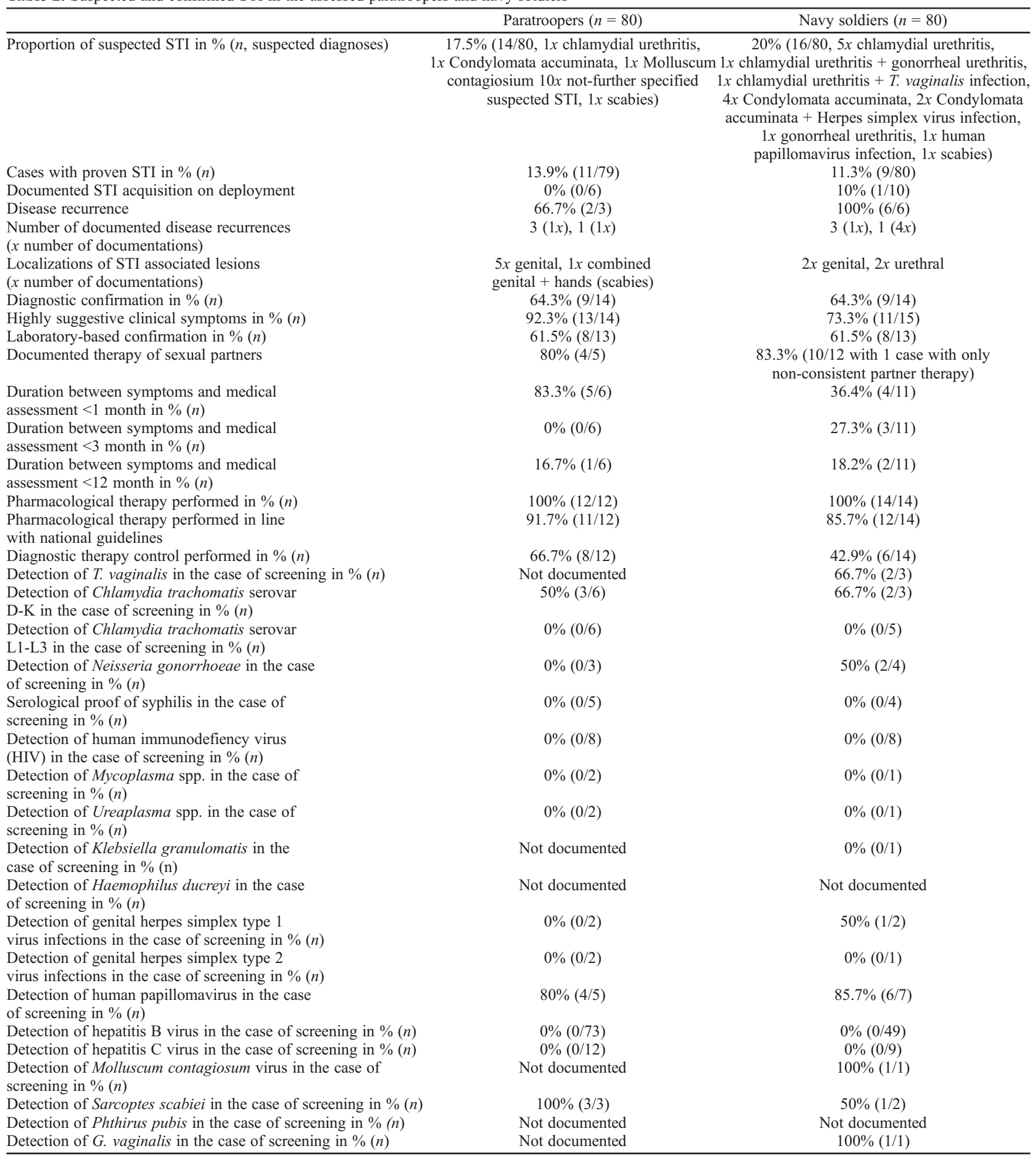


and Sarcoptes scabiei $(n=3)$ were observed in the group of the paratroopers. In the group of the navy soldiers, the spectrum of diagnosed pathogens was broader, comprising C. trachomatis $(n=2)$, Gardnerella vaginalis $(n=1)$, herpes simplex type 1 virus $(n=1)$, human papillomavirus $(n=6)$, Molluscum contagiosum virus $(n=1), N$. gonorrhoeae $(\mathrm{n}=2), S$. scabiei $(\mathrm{n}=1)$, and T. vaginalis $(\mathrm{n}=2)$.

\section{Discussion}

The cross-sectional study was performed to assess STIs in two German barracks for paratroopers and navy soldiers in order to estimate the need of medical STI prevention. It indicated considerable proportions of suspected or confirmed STIs in both populations, a broader spectrum of diagnosed STIs within the group of the navy soldiers, and room for improvement regarding diagnostic work-up. Indeed, nearly half of the suspected STIs were just syndromatically managed, using standard drugs like doxycycline or azithromycin, sometimes still even ciprofloxacin in spite of likely resistance of gonococci (data not shown).

The considerable rate of merely syndromatically managed STIs without broad pathogen-specific diagnosis does not allow definite conclusions regarding specific causative pathogens. Although too rarely performed in the populations assessed here, laboratory diagnosis of STIs is highly advisable to guide antimicrobial therapy in times of increasing resistance issues $[21,22]$ and due to the fact that co-infections with various STIs are frequent phenomena [16, 23]. The Robert Koch Institute as the German National Authority for Infectious Disease Prevention even encourages regular STI screenings in individuals showing promiscuous sexual activity [24]. Successful clinical management on a syndromatic basis may lead to a false feeling of safety, as asymptomatic carriage of STI-related pathogens in soldiers has been described as a frequent phenomenon [7]. Unfortunately, medical history of the assessed medical records in the here-described study rarely included sexual habits, making the associated need for diagnostic screening difficult to assess.

The uncertainty of military medical practitioners regarding necessity and appropriateness of diagnostic testing and screening for STIs is not restricted to Germany. In a survey conducted with US Air Force primary care providers, more than $80 \%$ only inconsistently and inconsequently offered STI screening options to soldiers from the MSM risk population [25]. Another study in the US armed forces suggested a tendency towards avoiding the clear-cut diagnosis of STIs in military medical records by coding them as cases of "unspecified urethritis" [26]. It is unclear whether or not respective considerations may have affected the decisions of the medical practitioners caring for the patients assessed in this study as well. Infrequently, however, the medical records provided hints that the soldiers preferred anonymous STI testing in peripheral laboratories over diagnostic assessments by their military physician in charge (data not shown).

In spite of the abovementioned risks and disadvantages, syndromatic management of symptoms indicative for STIs in the military setting is common as shown in a large US study retrospectively assessing more than 100,000 medical records. While a pathogen-specific STI diagnosis was set for $22 \%$ of female soldiers and $3.3 \%$ of male soldiers, inclusion of syndromatic diagnoses nearly doubled the percentages to $41 \%$ and $5.5 \%$, respectively. Risk factors for female soldiers with STIs comprised African-American origin, younger age, and fewer years of education in this large study, while there was a general trend for an increased risk of acquiring STIs with increasing numbers of years in the military service for both sexes [27]. Although the proportions observed in the here presented study were lower, the tendency of diagnostic workup in only about half of the cases of suspected STIs goes in a similarly undesirable direction.

The frequency of STIs in a population is necessarily interlinked with sexual habits. From a logical point of view, at least 3 individuals have to be involved in the transmission of an STI, because in order to transmit it, one must have acquired it with someone else first [28]. Theoretically, this simple fact might speak in favor of prevention programs propagating sexual abstinence or fidelity. In fact, however, previous "abstinence-only" prevention programs scored poorly, even leading to increased rates of both STI and unwanted pregnancies [28]. Similar experience by the armed forces medical service had been summarized in US-Surgeon General Dr. Jocelyn Elders' bon mot: "We know the vows of abstinence break far more easily than latex condoms." [28].

Accordingly, it seems worth focusing on the sexual habits of the population of interest. Unfortunately, no respective studies on German soldiers are internationally published, but a representative assessment of sexual behavior in the German population has been introduced in 2017 [29]. According to this assessment, the average number of sexual contacts during the lifetime of men and women is 10 and 5 for the "normal population", as well as 38 and 17 for individuals showing high-risk sexual behavior, respectively. Small percentages of individuals in stable sexual relationships have either open relationships $(2 \%)$ or relationships including a third partner (1\%). Quantitatively relevant minorities of $21 \%$ men and $15 \%$ women reported ever having had sexual contacts outside their main relationships [29].

Considering the high frequency of observed syndromes suggesting STIs in the assessed military medical records, the above-described German sexual "standard" behavior is hardly likely to explain the results of the study. Indeed, there are data strongly supporting the hypothesis of higher risk affinity in soldiers, also comprising their sexual encounters. In fact, it has been concluded that occupation-specific elements like operational tempo and ongoing exposure to occupational hazards enhance sexual risk behavior mediated by the military class habitus [30].

Numerous studies have been conducted to identify soldiers at a particular risk of acquiring STIs in order to support the design of suitable preventive approaches. Lacking awareness, knowledge, and perception of risks were early identified as factors facilitating sexual high-risk practices $[14,31]$. If the baseline knowledge is low as in a study from 2004 in Sierra Leone, simple procedures like educational programs can lead to increased adherence to protective approaches like condom use [31].

However, this does not necessarily apply under all circumstances. In a study with female US Marine Corps recruits, highest STI risks were associated with excellent knowledge on STIs and perception of higher individual STI acquisition risk next to young age, single marital status, unwillingness to use condoms, and preference of sex under the influence of alcohol or drugs, next to more region-specific associations like having had nonCaucasians as last sexual partners and residence in rural locations [32]. In another study, female US Marine Corps soldiers neglected STI acquisition risks associated with nonuse of condoms in spite of otherwise good risk perception [33], so sexual habits avoiding condom use seem to be of high social importance for this population. Reluctance towards condom use in spite of knowing the risk of STI acquisition is associated with increased risk-taking in other areas of social life like shown in a study with US Air Force recruits [34]. This means that there is a subgroup of soldiers willingly accepting higher STI acquisition risks in order to stick to preferred risky sexual habits.

Next to STI-specific knowledge, poor education in general and poor economic status were reported to be associated with 
high risks of STI acquisition [14, 35]. Further risk factors comprised lack of condom availability, heavy alcohol consumption and substance abuse prior to sexual contacts, parallel contacts to multiple sexual partners, sex with commercial sex workers, sex among men, receptive anal sex irrespective of gender, post-traumatic stress disorder (PTSD) as well as other psychiatric disorders like depression, stay in the military community about several years, meeting sexual partners at work, non-Caucasian ethnicity, unwanted sexual contacts, involuntary drug consumption, low rank, soldier status, and enlistment with a tendency towards lower percentages in married individuals [2, 14, 36-42].

In a Nigerian study, there was also an alarmingly high rate of more than $40 \%$ of soldiers neglecting STI by not seeking medical care prior to the next sexual contact, thus contributing to the spread of the diseases [43]. Similar proportions of reported STIs in female and male soldiers but higher rates of diagnosed STIs in female soldiers in a French study suggest higher screening coverage in female soldiers and higher readiness of female soldiers to consult a physician in the case of symptoms indicative of an STI [18, 44]. Especially for the navy soldiers in the here-presented study, considerable delay between onset of symptoms and medical assessment of STIs could be demonstrated as well.

Most interestingly, female gender by itself was identified as a risk factor for STI acquisition among soldiers [36], and family or personal-life stress, as well as psychological distress, were reported to affect risky sexual behavior in women more than in men [42]. French female soldiers were also more likely to have to endure forced sex compared to the rest of the French female population [44].

In a population of US shipboard military personnel, about half of the female soldiers with STIs had acquired those diseases from a regular partner or another service member. Altogether, the analysis indicated a complex sexual network among soldiers with a considerable proportion of sexual contacts outside the primary relationship and low adherence with condom use during sex with outside partners [45].

Regarding deployment status, reported study findings are partly contradictory. While some authors report less STIs in soldiers with experience of deployment [36] and sexual contacts on deployment mostly within the own military community itself [45], one study specifically suggested higher rates of STI on deployment, obviously driven by a proportion of risk-affine condom nonusers and enhanced by the deployment-related concentration within a restricted area of movement [40]. As far as suggested by the here presented data, a prominent role of deployment-associated STI acquisition could neither be confirmed for German paratroopers nor for German navy soldiers. Thus, the study is more likely to support the hypothesis of quantitatively dominating STI transmission independently from the deployment situation.

High STI rates in soldiers as indicated by various studies call for specifically adapted preventive approaches. The US Navy and Marine Corps established a Sexual Health and Responsibility Program (SHARP) to coordinate activity in the field of STI prevention programs [46]. In line with the known preventive effects of early diagnosis and treatment [47-49], military entry screenings for STIs have been recommended as a strategy of reducing STIs within the military community [50]. Data evaluating the preventive effects of prevention programs addressing STIs in the military setting are, however, still missing.

The need for reliable preventive strategies is stressed by previous observations indicating that not only immediate medical and social effects of STI have to be considered. Potential long-term consequences have been discussed as well. As suggested by a case-control study with the US soldiers, there might be a potential association of HSV-2 infections and onset of prostate cancer after a long latency period of several years [51]. Once infected, HSV-2 persists in the body for the patient's whole life.

A number of studies suggest that military prevention programs are challenging due to the need of good reasons for a subgroup of soldiers for not getting infected beyond the soldiers' mere compulsory duty of maintaining their individual health. There seems to be a proportion of highly risk-affine soldiers deliberately accepting potential STI infections to go on with risky sexual habits [32-34]. Such soldiers will have to be convinced of the value of intact sexual health first, or more simply said, that it is worth staying healthy and not deliberately ruining one's own physical integrity. This comprises not only the question "how" but also the question "why", may touch personal values and preferences, and is thus more complex than just giving a simple lecture on technical or behavioral prevention approaches.

The study has a number of limitations. First of all, the retrospective design limits the interpretability of the results. The same applies to the small numbers of assessed medical records. However, the analyzed records already indicated the main finding of high proportions of syndromes indicating STIs with yet too low rates of diagnostic workup and little data from the medical history. Due to this unambiguous observation, we abstained from assessing higher numbers of medical records. Another limitation is the fact that only two barracks were assessed, so the results cannot be considered as representative for the whole German armed forces.

Nevertheless, both the study and the literature review suggest an ongoing need for STI prevention and awareness of STI risks in the military. The German military medical service provides teaching on STIs and STI acquisition risks for both medical professionals and soldiers to increase this awareness. Examples for onsite prevention comprise providing of condoms on military ships, as well as providing of HIV pre-exposure and post-exposure prophylaxis in line with National guidelines. Most importantly, however, soldiers with and without symptoms after risky sexual encounters are encouraged to trustingly seek care at their military medical facilities, both for the option of counseling and for early detection and treatment of STIs [52].

\section{Conclusions}

The study indicated high rates of STI-related syndromes in German paratroopers and navy soldiers, stressing ongoing need for medical prevention. STI-specific diagnostic approaches still need to be facilitated for surveillance purposes, identification of asymptomatic or oligosymptomatic co-infections, and optimization of therapy in times of increasing antimicrobial drug resistance in STI-associated pathogens.

\section{Funding Sources}

No financial support was received for this study.

\section{Authors' Contribution}

CG, NGS, and HF jointly planned the study. CG collected and assessed the data and prepared the manuscript. All authors have jointly optimized and reviewed the manuscript.

\section{Conflicts of Interest}

There is nothing to declare. 


\section{References}

1. Rossi KR, Nowak G. Assessing the Burden of Chlamydia and Gonorrhea for Deployed and Active Duty Personnel Assigned Outside the USA. Mil Med. 2019;184(Suppl 1):21-7.

2. Armed Forces Health Surveillance Center. Sexually transmitted infections, active component, U.S. Armed Forces, 2000-2012. MSMR 2013;20:5-10

3. Webber BJ, Pawlak MT, Jones NM, Tchandja JN, Foster GA. Sexually transmitted infections in U.S. Air Force recruits in basic military training. MSMR. 2016;23:16-9.

4. Hakre S, Brett-Major DM, Singer DE, O'Connell RJ, Sateren WB, Sanchez JL, et al. Medical encounter characteristics of HIV seroconverters in the US Army and Air Force, 2000-2004. J Acquir Immune Defic Syndr. 2011;56:372-80.

5. Cohen JA, Sellers A, Sunil TS, Matthews PE, Okulicz JF. Herpes simplex virus seroprevalence and seroconversion among active duty US air force members with HIV infection. J Clin Virol. 2016;74:4-7.

6. Mindel A, Sawleshwarkar S. Condoms for sexually transmissible infection prevention: politics versus science. Sexual Health. 2008;5:1-8.

7. Carpenter RJ, Refugio ON, Adams N, O'Brien KP, Johnson MD, Groff $\mathrm{HL}$, et al. Prevalence and factors associated with asymptomatic gonococcal and chlamydial infection among US Navy and Marine Corps men infected with the HIV: a cohort study. BMJ Open. 2013;3:5

8, Tzeng JS, Clark LL, Garges EC, Otto JL. Epidemiology of Sexually Transmitted Infections among Human Immunodeficiency Virus Positive United States Military Personnel. J Sex Transm Dis. 2013;2013:610258.

9. Rogstad KE. Sexually transmitted infections and travel. Curr Opin Infect Dis. 2019;32:56-62

10. Deiss R, Byrne M, Echols SM, Cammarata SM, Potswald L, Gomez E, et al. Extragenital chlamydia infection among active-duty women in the United States Navy. Mil Med Res. 2019;6:3.

11. Greene JP, Stafford E. Prevalence of Chlamydia trachomatis among active duty male soldiers reporting to a troop medical clinic for routine health care. South Med J. 2007;100:478-481.

12. da Motta LR, Sperhacke RD, Adami AG, Kato SK, Vanni AC, Paganella MP, de Oliveira MCP, et al. Syphilis prevalence and risk factors among young men presenting to the Brazilian Army in 2016: Results from a national survey. Medicine. 2018;97:e13309.

13. Sperhacke RD, da Motta LR, Kato SK, Vanni AC, Paganella MP, Oliveira MCP, et al. HIV prevalence and sexual behavior among young male conscripts in the Brazilian army, 2016. Medicine. 2018;97(1S Suppl 1):S25-31.

14. Anastario M, Manzanero R, Blanco R, Reyes E, Jaramillo R, Black L, et al. HIV infection, sexual risk behaviour and condom use in the Belize defense force. Int J STD AIDS. 2011;22:73-9.

15. Todd CS, Nasir A, Mansoor GF, Sahibzada SM, Jagodzinski LL, Salimi F, et al. Cross-sectional assessment of prevalence and correlates of blood-borne and sexually-transmitted infections among Afghan National Army recruits. BMC Infect Dis. 2012;12:196.

16. Kim HJ, Park JK, Park SC, Kim YG, Choi H, Ko JI, et al. The prevalence of causative organisms of community-acquired urethritis in an age group at high risk for sexually transmitted infections in Korean Soldiers. J R Army Med Corps. 2017;163:20-2.

17. Horner P, Donders G, Cusini M, Gomberg M, Jensen JS, Unemo M. Should we be testing for urogenital Mycoplasma hominis, Ureaplasma parvum and Ureaplasma urealyticum in men and women? - a position statement from the European STI Guidelines Editorial Board. J Eur Acad Dermatol Venereol 2018;32:1845-51.

18. Duron S, Panjo H, Bohet A, Bigaillon C, Sicard S, Bajos N, et al. Prevalence and risk factors of sexually transmitted infections among French service members. PLoS One. 2018;13:e0195158

19. Parker RD, Rüütel K. Sexually Transmitted Infections - Prevalence, Knowledge and Behaviours among Professional Defence Forces in Estonia: a Pilot Study. Cent Eur J Public Health 2017;25:11-4.

20. Korzeniewski K. Urogenital Chlamydia trachomatis in the environment of soldiers from the Polish Special Forces. Ann Agric Environ Med. 2019;26:51-4.

21. Costa-Lourenco APRD, Barros Dos Santos KT, Moreira BM, Fracalanzza SEL, Bonelli RR. Antimicrobial resistance in Neisseria gonorrhoeae: history, molecular mechanisms and epidemiological aspects of an emerging global threat. Braz J Microbiol. 2017;48:617-28.

22. Murray GL, Bradshaw CS, Bissessor M, Danielewski J, Garland SM, Jensen JS, et al. Increasing Macrolide and Fluoroquinolone Resistance in Mycoplasma genitalium. Emerg Infect Dis. 2017;23:809-12

23. Xian Y, Zhu B, Zhang X, Ma P, Wei Y, Xia H, et al. Risk factors associated with sexually transmitted infections among HIV infected men who have sex with men. PLoS One. 2017;12:e0170635.

24. Robert Koch-Institut. Personen mit häufig wechselnden Geschlechtspartnern sollten spezielle Angebote der Untersuchung auf STD erhalten. Gemeinsame Empfehlung des RKI, der DSTDG, der DAIG, der DAGNÄ und der DGHM (gekürzte Fassung). Epi Bull. 2013;36:289.

25. Tong RL, Lane J, McCleskey P, Montenegro B, Mansalis K. A pilot study describing knowledge and practices in the health care of men who have sex with men by U.S. Air Force primary care providers. Mil Med. 2013;178:e248-54.

26. Armed Forces Health Surveillance Center. Relationships between diagnoses of sexually transmitted infections and urinary tract infections among male service members diagnosed with urethritis, active component, U.S Armed Forces, 2000-2013. MSMR. 2014;21:14-7.

27. Deiss R, Bower RJ, Co E, Mesner O, Sanchez JL, Masel J, et al. The Association between Sexually Transmitted Infections, Length of Service and
Other Demographic Factors in the U.S. Military. PLoS One. 2016;11: e0167892.

28. Sing A. Zur Epidemiologie von sexuell übertragbaren Erkrankungen: der Beitrag der Sozialen Netzwerk-Analyse zu einem komplexen Feld. Mikrobiologe. 2011;21:150-160.

29. Haversath J, Gärttner KM, Kliem S, Vasterling I, Strauss B, Kröger C. Sexual Behavior in Germany. Dtsch Arztebl Int. 2017;114:545-50.

30. Anastario MP, Hallum-Montes R, Reyes E, Manzanero R, Chun H Toward a social theory of sexual risk behavior among men in the Armed Services: understanding the military occupational habitus. Cult Med Psychiatry. 2013;37:737-55.

31. Larsen MM, Sartie MT, Musa T, Casey SE, Tommy J, Saldinger M. Changes in HIV/AIDS/STI knowledge, attitudes and practices among commercial sex workers and military forces in Port Loko, Sierra Leone. Disasters. 2004;28:239-54

32. Boyer CB, Pollack LM, Becnel J, Shafer MA. Relationships among sociodemographic markers, behavioral risk, and sexually transmitted infections in U. S. female Marine Corps recruits. Mil Med. 2008;173:1078-84.

33. Cooper TV, DeBon M, Haddock CK, Esquivel DR, Klesges RC, Lando $\mathrm{H}$, et al. Demographics and risky lifestyle behaviors associated with willingness to risk sexually transmitted infection in Air Force recruits. Am J Health Promot. 2008;22:164-7.

34. Pollack LM, Boyer CB, Weinstein ND. Perceived risk for sexually transmitted infections aligns with sexual risk behavior with the exception of condom nonuse: data from a nonclinical sample of sexually active young adult women. Sex Transm Dis. 2013;40:388-94.

35. Szwarcwald CL, Castilho EA, Barbosa Jr A, Gomes MR, Costa EA, Maletta BV, et al. Risk behavior among Brazilian Military conscripts, 1998: an study of HIV infections following socioeconomic differences. Cad Saude Publica. 2000;16(Suppl 1):113-28.

36. Hakre S, Oyler RJ, Ferrell KA, Li F, Michael NL, Scott PT, et al. Chlamydia trachomatis infection rates among a cohort of mobile soldiers stationed at Fort Bragg, North Carolina, 2005-2010. BMC Public Health. 2014;14:181.

37. Harbertson J, Grillo M, Zimulinda E, Murego C, Brodine S, May S, et al. HIV seroprevalence, associated risk behavior, and alcohol use among male Rwanda Defense Forces military personnel. AIDS Behav. 2013;17:1734-45.

38. Harbertson J, Grillo M, Zimulinda E, Murego C, Cronan T, May S, et al. Prevalence of PTSD and depression, and associated sexual risk factors, among male Rwanda Defense Forces military personnel. Trop Med Int Health. 2013;18:925-33.

39. Harbertson J, Scott PT, Lemus H, Michael NL, Hale BR. CrossSectional Study of Sexual Behavior, Alcohol Use, and Mental Health Conditions Associated With Sexually Transmitted Infections Among Deploying Shipboard US Military Personnel. Mil Med. 2019; [Epub ahead of print]:doi: 10.1093/milmed/usz070.

40. Harbertson J, De Vera K, Scott PT, Li Y, Shaffer RA, Michael NL, et al. Longitudinal survey of condom use across a US Navy and Marine Corps shipboard deployment. BMJ Open. 2019;9:e028151.

41. Ortiz DJ, Bing EG, Boyer CB, Russak SM, De Deus FJ, Ernesto F. Evidence-based recommendations for prevention of human immunodeficiency virus and sexually transmitted infections in the Angolan Armed Forces: challenges and opportunities at the end of 30 years of war. Mil Med. 2005;170:327-32.

42. Stahlman S, Javanbakht M, Cochran S, Hamilton AB, Shoptaw S, Gorbach PM. Self-reported sexually transmitted infections and sexual risk behaviors in the U.S. Military: how sex influences risk. Sex Transm Dis. 2014;41:359-64

43. Okeke CE, Onwasigwe CN, Ibegbu MD. The effect of age on knowledge of HIV/AIDS and risk related behaviours among army personnel. Afr Health Sci. 2012;12:291-6.

44. Duron S, Bohet A, Panjo H, Bajos N, Migliani R, Marimoutou C, et al. Sexual health in the French military: a multidimensional and gendered perspective. BMC Public Health. 2018;18:750.

45. Harbertson J, Scott PT, Moore J, Wolf M, Morris J, Thrasher S, et al Sexually transmitted infections and sexual behaviour of deploying shipboard US military personnel: a cross-sectional analysis. Sex Transm Infect. 2015;91:581-8.

46. MacDonald MR. Sexual Health and Responsibility Program (SHARP): preventing HIV, STIs, and unplanned pregnancies in the navy and marine corps. Public Health Rep. 2013;128(Suppl 1):81-8.

47. Hahn A, Schwarz NG, Meyer T, Frickmann H.PCR-based rapid diagnostic tests as a strategy for preventing infections with sexually transmitted diseases - a "diagnostics-as-prevention" modelling approach. Lett Appl Microbiol. 2018;67:420-4.

48. Hahn A, Hinz R, Meyer T, Loderstädt U, Herchenröder O, Meyer CG, et al. HIV prevention strategies and risk of infection: a model-based analysis. Epidemiol Infect. 2018;146:1015-25.

49. Hahn A, Hinz R, Meyer T, Loderstädt U, Herchenröder O, Meyer CG, et al. Diagnostics as prevention - a rapid testing-based strategy of sex workers against sexual HIV exposure. Eur J Microbiol Immunol (Bd.). 2018;8:47-52.

50. Parker RD, Regier M, Widmeyer J, Rüütel K. HIV/STI prevalence study among military conscripts in Estonia. J Community Health. 2015;40:271-5

51. Dennis LK, Coughlin JA, McKinnon BC, Wells TS, Gaydos CA, Hamsikova E, et al. Sexually transmitted infections and prostate cancer among men in the U.S. military. Cancer Epidemiol Biomarkers Prev. 2009;18:2665-71.

52. Frickmann H, Gottwald C, Maaßen W. "How do I put it?" - Case reports on well-tolerated HIV post-exposure prophylaxis on deployment in the tropics. International Review of the Armed Forces Medical Services. 2017;90:47-58. 